\title{
LIEŽUVINIO SKYDLIAUKĖS LATAKO CISTA: KLINIKINIS ATVEJIS
}

\author{
Darius Bajorinas ${ }^{1}$, Kamilè Macyte் $\dot{e}^{2}$ \\ ${ }^{1}$ Respublikinè Šiauliu ligoninè, Ausu, nosies, gerklès ligu skyrius, \\ ${ }^{2}$ Lietuvos sveikatos mokslu universitetas, Medicinos akademija, Medicinos fakultetas
}

Raktažodžiai: liežuvinio skydliaukès latako cista, igimti kaklo dariniai, cistos ekstirpacija.

\begin{abstract}
Santrauka
Liežuvinio skydliaukès latako cistos - dažniausi igimti cistiniai kaklo dariniai. İprastai šios cistos diagnozuojamos vaikams ir jauniems pacientams iki 20 metų, tačiau literatūroje aprašyta atvejų, kai liežuvinio skydliaukès latako cista buvo diagnozuota vyresniems nei 50 metų pacientams. Šiame straipsnyje pateikiama kaklo cistų klasifikacija, plačiau aptariamas liežuvinio skydliaukès latako cistų išsivystymas, klinikiniai požymiai, diagnostikos ir gydymo galimybès bei pristatomas klinikinis atvejis, kai cista diagnozuota ir sèkmingai pašalinta 40 metų pacientui.
\end{abstract}

\section{Ivadas}

Kaklo cistos - tai cistiniai dariniai kaklo priekiniame arba šoniniame paviršiuje, iškloti epiteliu ir užpildyti skystu, gleivingu, kietu ar dujiniu turiniu [1]. Pagal kilmę kaklo cistos skirstomos ị igimtas ir ịgytas. Igytos kaklo cistos dažniausiai susiformuoja po uždegiminès kilmès kaklo ligų [2]. Joms priskiriama: 1) abscesai, 2) cistinès mazginès metastazès (cystic nodal metastasis), 3) neurogeninès kilmès navikai $[2,3]$. Igimtos kaklo cistos formuojasi embriogenezès metu iš nesuaugusio antrojo žiaunų lanko plyšio arba išsiplètus embriono liežuviniam skydliaukès latakui [4,5]. Igimtos kaklo cistos pagal sutrikusios embriogenezès kilmę klasifikuojamos ị: 1) liežuvinio skydliaukès latako (kitaip - priekines, vidurio linijos) cistas, 2) žiaunų lanko (kitaip - šonines, brachiogenines) cistas, 3) limfinès sistemos apsigimimus $[2,4,5]$. Šiame straipsnyje plačiau apžvelgiamos liežuvinio skydliaukès latako cistos.

Tyrimo tikslas - remiantis naujausiomis mokslinėmis publikacijomis, apžvelgti kaklo cistų klasifikaciją, plačiau aptarti liežuvinio skydliaukès latako cistų išsivystymą, klinikinius požymius, diagnostikos ir gydymo galimybes bei pristatyti klinikini atvejị, kai cista diagnozuota ir sėkmingai pašalinta 40 metų pacientui.

\section{Tyrimo medžiaga ir metodai}

Atlikta 9 publikacijų mokslinė apžvalga. Straipsniai atrinkti naudojantis PubMed ir ScienceDirect duomenų bazèmis. I apžvalgą įtrauktos ne senesnès nei dešimties metų publikacijos lietuvių ir anglų kalba. Pristatytas klinikinis atvejis, kai cista diagnozuota ir sẻkmingai pašalinta 40 metų pacientui.

\section{Tyrimo rezultatai}

Embriogenezė ir anatomija. Embriogenezès metu liežuvinis skydliaukès latakas kartu su poliežuviniu kaulu formuojasi iš antrojo žiaunų lanko [6]. Skydliaukè pradeda formuotis ketvirtają embriogenezès savaitę kaip ryklès dugno divertikulas ir nuo skydliaukès išgaubos (foramen caecum) leidžiasi liežuviniu skydliaukès lataku (ductus thyroglossus) i kaklo priekinę dali $[2,4,5]$. Penktają embriogenezès savaitę prasideda ir iki 4 mèn. tęsiasi šio latako involiucija, kuriai sutrikus ir kanalui užakus, ima formuotis liežuvinio skydliaukès latako cista, fistulè arba antis [2,4,5]. Cista gali susiformuoti bet kuriame liežuvinio skydliaukès latako aukštyje: poliežuvinio kaulo projekcijoje, virš poliežuvinio kaulo, po poliežuviniu kaulu, liežuvio šaknyje arba gerklose [2]. Dažniausiai nustatomos po poliežuviniu kaulu esančios cistos (skirtingų autorių duomenimis, dažnumas svyruoja nuo 25 iki 65 proc.) [2,5,7]. Apie 70-90 proc. atvejų cistos dèstosi vidurineje kaklo linijoje, šalia skydinès kremzlès, tačiau gali būti nustatomos ir paramedialiai, dažniau kairèje pusėje [2].

Histologija. Liežuvinio skydliaukès latako cistos gali būti vienkamerinès arba daugiakamerinès. Cistas dažniausiai iškloja virpamasis kvejpuojamasis epitelis, kartais randamas ragejjantis, pereinantis iš virpamojo ị ragejjantị arba skydliaukès audiniui būdingas epitelis [6]. Cistos dažniausiai būna užpildytos gleivètu turiniu arba, esant infekcijai, pūliais [6]. Mažiau nei 1 proc. šių kaklo cistų tampa piktybinèmis [2]. 
Dažniausiai piktybiniai dariniai nustatomi vyresnio amžiaus pacientams [2,4-6]. Labiausiai paplitusi papiliarinè karcinoma ( 92,1 proc. atvejų) ir ragèjančių ląstelių karcinoma (4,3 proc. atvejų) [6].

Klinika. Liežuvinio skydliaukès latako cistos diametras svyruoja nuo $0,5 \mathrm{~cm}$ iki $4 \mathrm{~cm}[2,4]$. Dažniausiai tai besimptomis darinys, sukeliantis kosmetinius defektus [8]. Prasidejjus cistos infekcijai, darinys tampa skausmingas, išryškejja vietinès infekcijos požymiai, disfagija, disfonija, galimas bendras negalavimas, karščiavimas [2,4,5]. Retais atvejais (apie 10 proc.), susiformavus abscesui, cista plyšta ir susidaro fistule, iš kurios teka pūlingos išskyros [2]. Fistulès dažniau susiformuoja vaikams, nei suaugusiems [2,8].

Diagnostika. Cistos diagnostika remiasi apžiūros, palpacijos, ultragarsinio ištyrimo, kompiuterinès tomografijos, magnetinio rezonanso ir histopatologinio ištyrimo duomenimis. Apžiūrint ir čiuopiant liežuvinio skydliaukès latako cista stebima kaip įvairaus dydžio, paslankus, fliuktuojantis, minkštos konsistencijos, lygaus paviršiaus, neskausmingas kaklo darinys $[5,8]$. Cista juda iškišant liežuvị ir ryjant seiles [1]. Kaklo audinių ultragarsinis tyrimas (UG) yra pirmo pasirinkimo tyrimas, diagnozuojant liežuvinio skydliaukès latako cistas $[2,5,9]$. Šio tyrimo metu nustatoma cistos lokalizacija, santykis su aplinkiniais organais, ịvertinama skydliaukès struktūra $[1,2,5]$. Cista UG stebima kaip aiškių ribų, lygiomis, plonomis sienelèmis, užpildytas skystu, neechogenišku arba hipoechogenišku turiniu, neturintis vidinès kraujotakos darinys [9]. Esant infekcijai - cistos sienelès nelygios, sustorejusios, aplink cistą stebimi uždegiminiai pokyčiai ir suaktyvejusi kraujotaka [9]. Kompiuterinès tomografijos (toliau KT) vaizduose cistos stebimos kaip homogeniniai, plonasieniai, skysčiu užpildyti, mažo tankio dariniai [9].
Lyginant su UG tyrimu, KT leidžia geriau ịvertinti liežuvinès skydliaukès latako cistos santykị su kitomis anatominèmis struktūromis, yra naudingesnis diferencinei diagnostikai ir padeda tiksliau įvertinti darinio piktybiškumą, tačiau šiam tyrimui naudojama apšvita [9]. Magnetinio rezonanso (MRT) T1 režimu cista stebima kaip aukšto arba žemo signalo intensyvumo darinys, priklausomai nuo to, ar cista komplikuota, T2 režimu - kaip aukšto signalo intensyvumo darinys [9]. Lyginant KT ir MRT, KT tyrimas naudingesnis ir leidžia geriau identifikuoti poliežuvinio kaulo srityje esančias cistas, o MRT tyrimas - liežuvio šaknies projekcijoje esančius darinius [9]. Norint diagnozuoti liežuvinę skydliaukès latako cistą, darinị reikia diferencijuoti nuo: dermoidinès cistos, ektopinès skydliaukès, limfadenopatijos, limfmazgio absceso, laringocelès, limfinès sistemos apsigimimų, lipomos, hemangiomos, teratomos, ateromos ir žiaunų lanko cistos [1].

Gydymas. Liežuvinio skydliaukès latako cistos gydomos chirurgiškai - atliekama cistos ekstirpacija [1,4]. Operacijos metu cista pašalinama su kapsule $[1,2,4,5]$. Jeigu cista nustatoma poliežuvinio kaulo projekcijoje - atliekama šio kaulo kūno vidurinio trečdalio rezekcija (Sistrunk procedure) ir tolimesnès ductus suprahyoideus dalies rezekcija [4,5]. Ši operacija yra radikalesnè, tačiau, nepašalinus poliežuvinio kaulo, 3-5 proc. atvejų galimi cistų recidyvai $[1,2,4,5]$.

\section{Klinikinis atvejis}

40 metų vyras kreipèsi ị ausų, nosies ir gerklès (ANG) ligų gydytoją dèl kaklo darinio, atsiradusio prieš maždaug 4 ménesius. Paciento teigimu, darinys neskausmingas, pastaruoju metu nedidèjantis, nesukeliantis jokių gretutinių simptomų. Apžiūrint kaklo priekinèje vidurinèje dalyje, žemiau

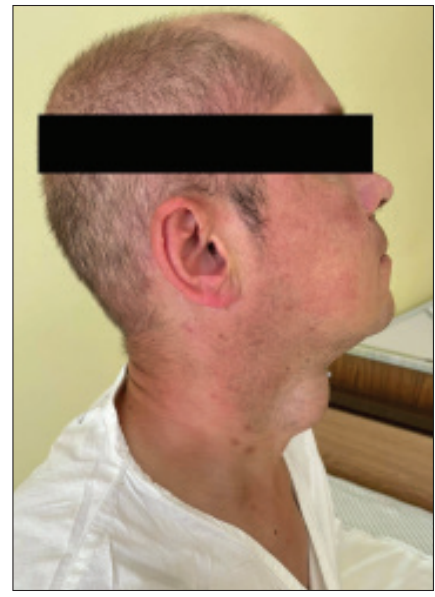

1 pav. Pacientas prieš operaciją. Darinys kaklo priekinèje dalyje

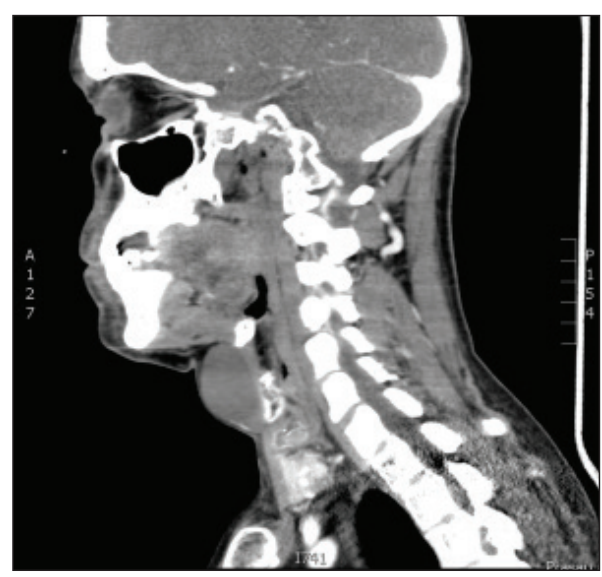

2 pav. KT. Sagitalinė plokštuma. Aiškių ribų cistinis darinys žemiau poliežuvinio kaulo

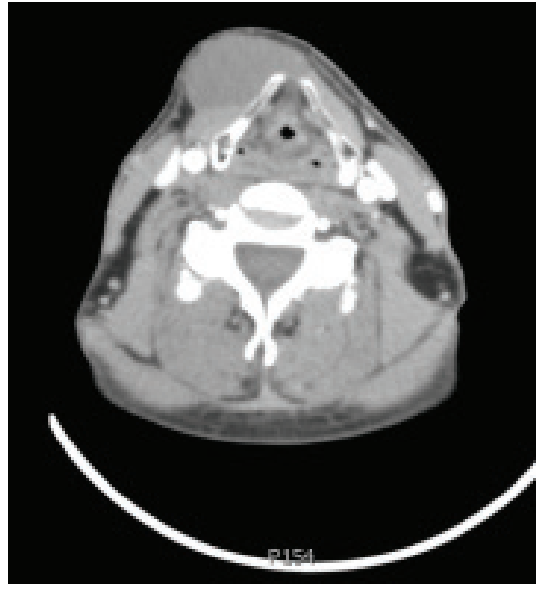

3 pav. KT. Horizontalinė plokštuma. Prie skydinès kremzlès dešinès plokštelès išorinio krašto prigludęs darinys 


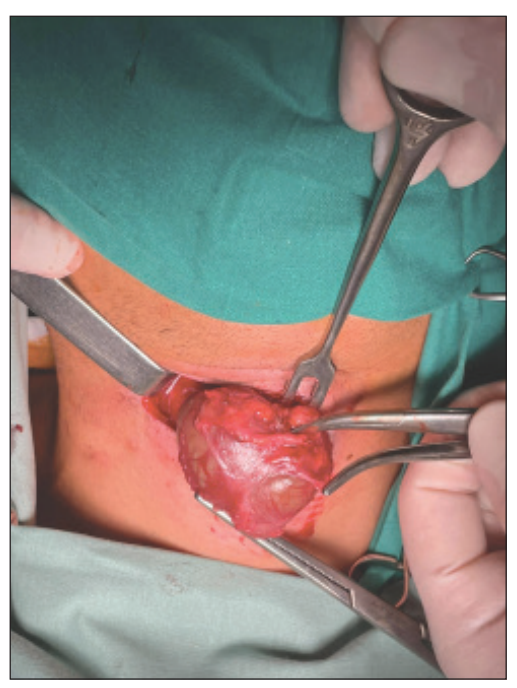

4 pav. Chirurginès operacijos vaizdas. Fiksuota cistos kapsulè

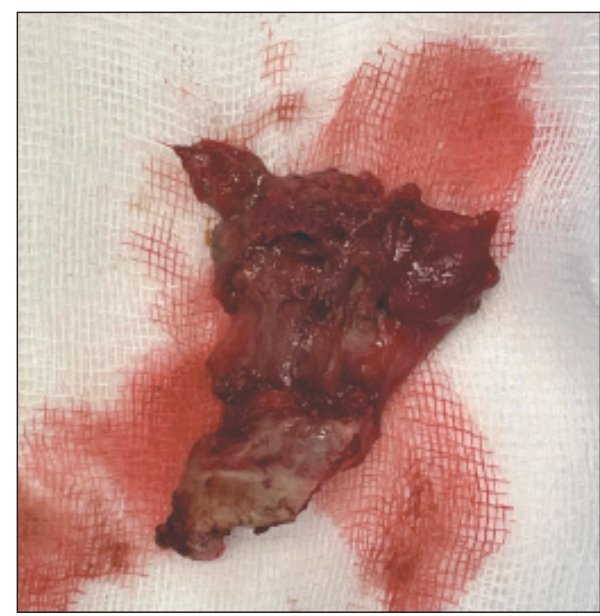

5 pav. Chirurginès operacijos vaizdas. Pašalintas cistos ir poliežuvinio kaulo kompleksas

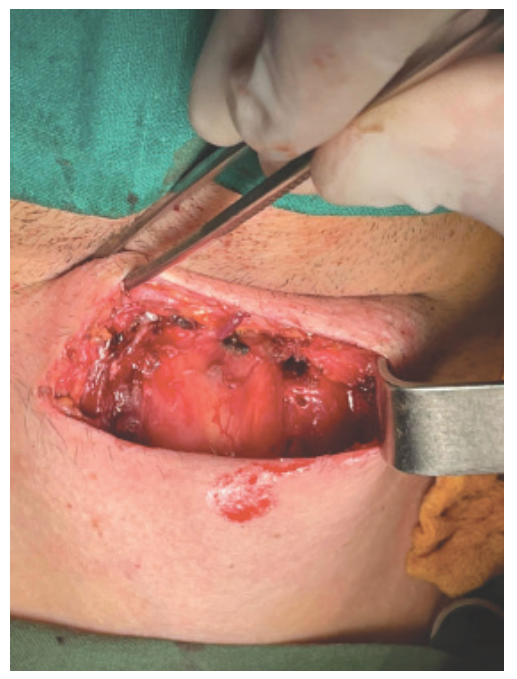

6 pav. Chirurginès operacijos vaizdas. Pooperacinè ertmé poliežuvinio kaulo, stebimas maždaug $4 \mathrm{x} 4 \mathrm{~cm}$ darinys (1 pav.). Palpuojant darinys paslankus, minkštos konsistencijos, neskausmingas. Juda ryjant seiles ir iškišant liežuvị. Faringoskopuojant ryklès gleivinè rami, lygi, žiočių lankai simetriški, minkštojo gomurio judrumas nesutrikęs. Endoskopuojant stebima ryklès gleivinè, liežuvio šaknis rami, lygi, balso plyšys laisvas, balso klostès lygios, ramios, judrios, kriaušinės kišenės laisvos, papildomų darinių nestebima. Atlikus kaklo minkštujų audinių UG, poodiniuose audiniuose stebimas žemo echogeniškumo su gausiais echoteigiamais, koloidą primenančiais intarpais, ribotas, aiškių ir lygių ribų darinys, panašiausias ị tirštu turiniu užpildytą cistą. Kaklo minkštujų audinių KT su intraveniniu kontrastavimu vaizduose matomas $2,5 \times 4,0 \times 4,3 \mathrm{~cm}$ dydžio, priekinèje kaklo dalyje, labiau dešinèje kaklo puseje, žemiau poliežuvinio kaulo esantis cistinio tankio, aiškių ribų, be kontrastinès medžiagos kaupimo požymių darinys, prigludęs prie skydinès kremzlès dešinès plokštelès išorinio krašto (2,3 pav.). Remiantis klinikinio ištyrimo ir instrumentinių tyrimų duomenimis, pacientui nustatyta preliminari diagnoze - liežuvinio skydliaukès latako cista. Skirtas chirurginis gydymas planine tvarka - darinio pašalinimas. Bendrinèje endotrachèjinèje nejautroje atliktas horizontalus, apie $5 \mathrm{~cm}$ ilgio kaklo odos pjūvis cistos projekcijoje, tarp viršutinio skydinès kremzlès krašto ir poliežuvinio kaulo. Išdalinti aplinkiniai audiniai iki linea alba, cista su kapsule fiksuota (4 pav.), išdalinta poliežuvinio kaulo medialine dalis ir atlikta vidurinio trečdalio kaulo rezekcija. Kaulas pašalintas viename komplekse su cista (5 pav.). Po poliežuviniu kaulu esančiame liežuviniame skydliaukès latake cistos eigos nestebèta. I likusią pooperacinę ertmę ( 6 pav.) ịvestas ir fiksuotas drenas. Žaizda susiūta pasluoksniui (raumenys, poodis, oda) tirpiais siūlais. Pašalintas darinys ištirtas histologiškai (išvada - liežuvinio skydliaukès latako cista). Pacientui skirta profilaktinè antibiotikoterapija benzilpenicilinu ( $2 \mathrm{ml} \mathrm{VV} 4$ k/d). Skausmui malšinti skirta diklofenako natrio druska $(75 \mathrm{mg} \mathrm{i} / \mathrm{r}$ pagal poreiki). Pooperacinė eiga sklandi, trečią dieną po operacijos pacientas išleistas namo.

\section{Išvados}

1. Liežuvinio skydliaukès latako cistos - kaklo dariniai, dažniausiai nustatomi jauno amžiaus pacientams.

2. Cistos diagnozuojamos remiantis klinikinès apžiūros duomenimis ir vaizdo tyrimais: kaklo minkštujų audinių UG, KT, MRT.

3. Pagrindinis šių cistų gydymo būdas - chirurginis cistos pašalinimas. Jeigu cista nustatoma poliežuvinio kaulo projekcijoje, atliekama šio kaulo kūno vidurinio trečdalio rezekcija (Sistrunk procedure).

4. Pašalinus cistą, būtinas histopatologinis ištyrimas dèl galimos suvėžèjimo rizikos, ypač vyresnio amžiaus pacientams.

\section{Literatūra}

1. Lesinskas E. Ausų, nosies ir gerklès ligos. Vilniaus universiteto leidykla, 2014.

2. Luna MA, Pineda-Daboin K. Cysts and unknown primary and secondary tumours of the neck and neck dissection. Pathology of the Head and Neck 2014:264-280.

https://doi.org/10.1007/3-540-30629-3_9 


\section{6}

3. Kumar A, Teh A, Vartevan A. Cystic neck mass. Journal of the American Osteopathic College of Radiology 2018;7(4):20-22. http://cdn.agilitycms.com/jaocr/PDFs/Issues/Vol7Iss4CR1 Kumar.pdf(2021-08-23)

4. Righini CA, Hitter A, Reyt E, Atallah I. Thyroglossal duct surgery. Sistrunk procedure. European Annals of Otorhinolaryngology. Head and Neck Diseases 2016;133:133-136. https://doi.org/10.1016/j.anorl.2015.11.008

5. Melissa A et all. Clinical practice guideline: evaluation of the neck mass in adults. Otolaryngology-Head and Neck Surgery 2017;157(2S):SI-S30. https://doi.org/10.1177/0194599817722550

6. Thompson LDR. Thyroglossal duct cyst. ENT-Ear, Nose \&Throat Journal 2017;96(2):54-55. https://doi.org/10.1177/014556131709600204

7. Prasad KC, Dannana NK, Prasad SC. Thyroglossal duct cyst: an unusal presentation. ENT-Ear, Nose\&Throat Journal 2006;85(7):454-456. https://doi.org/10.1177/014556130608500720

8. Hobbs C, Bova R. Necklumps. A guide to assessment and management. Medicine Today 2010;11(4):26-34. https://entthyroid.com.au/wp-content/uploads/2015/03/ Medicine-Today-Neck-Lumps-Ron-Bova.pdf(2021-08-25)

9. Islam O. Thyroglossal duct cyst imaging. Radiology 2017. https://emedicine.medscape.com/article/1346365overview\#showall(2021-08-25)

\section{THYROGLOSSAL DUCT CYST: CASE REPORT}

D. Bajorinas, K. Macytė

Keywords: thyroglossal duct cyst, congenital neck masses, Sistrunk procedure.

Summary

Thyroglossal duct cysts (TDC) are the most common congenital neck masses. They are usually diagnosed in childhood (occur in patients younger than 20 years), although, according to a literature, there are some patients of whom are aged over 50 years. This article will discuss classification of neck cysts, embryology, clinical significance, diagnostic and treatment of TDC and present a clinical case of 40 years old patient with TDC.

Correspondence to: kamilemacite@gmail.com

Gauta 2021-09-24 